\title{
Effect of electric field in liquid phase oxidation of benzhydrol by aqueous hydrogen peroxide
}

\author{
Amelia Boon Hoo, Hadi Nur* \\ Ibnu Sina Institute for Fundamental Science Studies, Universiti Teknologi Malaysia, \\ Received 30 March 2011, Revised 30 April 2011, Accepted 19 May 2011, Available online 25 June 2011.
}

\begin{abstract}
Electric-field-induced oxidation of benzhydrol to benzophenone over conducting surface containing titanium dioxide has been carried out by using hydrogen peroxide as oxidant. The results suggest the occurrence of synergistic effect of electric field and titania in which the interphase area between the titania particles and conducting surface is the most active region for the reaction. The electrical field on the generation of surface charge to induce the adsorption of organic substrate has also been confirmed by dye adsorption experiments.
\end{abstract}

| Electric-field-induced catalytic oxidation; Benzohydrol; Titania|

® 2011 Ibnu Sina Institute. All rights reserved. http://dx.doi.org/10.11113/mjfas.v7n1.219

\section{INTRODUCTION}

In general, liquid phase reactions can be enhanced by manipulation of relevant local environmental conditions [1]. The rate of the reaction and selectivity might increase. Reactions may also be enhanced by increasing the temperature or pressure. The mechanism for this enhancement is usually expressed in terms of increasing the likelihood of overcoming the activation energy. It is an objective of the present study to enhance chemical reactions without requiring a high temperature of the reaction environment by applying the electric field. One considers that the electric field may affect the molecular processes of the catalytic reaction on the heterogeneous catalyst's surface [2-7]. When a substrate hits on a solid surface from a liquid phase, there are a number of possible outcomes [8]. The substrate molecule may simply either bounce back or be adsorbed. It is the latter case that carries the most interesting possibilities. The interaction with the substrate of the surface can be so strong that the molecule dissociates into constituent groups or atoms. The substrate molecule can also react directly with surface groups and change the chemical properties of the surface. A third possibility is that the adsorbed molecule encounters another previously adsorbed one and there is a binary chemical reaction on the surface.

Based on the above consideration, it is of interest to explore the effect of electric field on the liquid phase reaction over a heterogeneous catalyst's surface. Here, the effect of electric field enhanced on catalytic oxidation of benzhydrol to benzophenone was investigated. The oxidation of benzhydrol to benzophenone was studied in the system containing titania $\left(\mathrm{TiO}_{2}\right)$ attached on the conducting carbon grease under electric field.

\section{EXPERIMENTAL}

\subsection{The catalyst system}

Fig. 1 shows the schematic representation of PPy$\mathrm{TiO}_{2}$ mixture attached to carbon grease which is supported by the bronze foil. The titania $\left(\mathrm{TiO}_{2}\right)$ powder with anatase structure was supplied by Merck. Polypyrrole (PPy) containing proprietary organic sulfonic acid dopant with electrical conductivity $10-40 \mathrm{~S} \mathrm{~cm}^{-1}$ was supplied by Aldrich. Carbon conductive grease supplied by MG Chemicals was used to stick PPy titanium oxide powder on the bronze foil. A series of $\mathrm{PPy}-\mathrm{TiO}_{2}$ mixture in various proportions $\left(0-100 \% \quad \mathrm{TiO}_{2}\right)$ was prepared by stirring manually the $\mathrm{PPy}-\mathrm{TiO}_{2}$ particles with a spatula until uniformly mixture was obtained. In this mixture, PPy act as conducting “solid” solvent to dilute $\mathrm{TiO}_{2}$. The bronze foil coated with carbon grease was dipped into the specified $\mathrm{PPy}-\mathrm{TiO}_{2}$ mixture. Direct current voltage-stabilized power source was used in supplying electric field in catalyst system. A multi meter was used for measurement of the current and voltage in the system. 


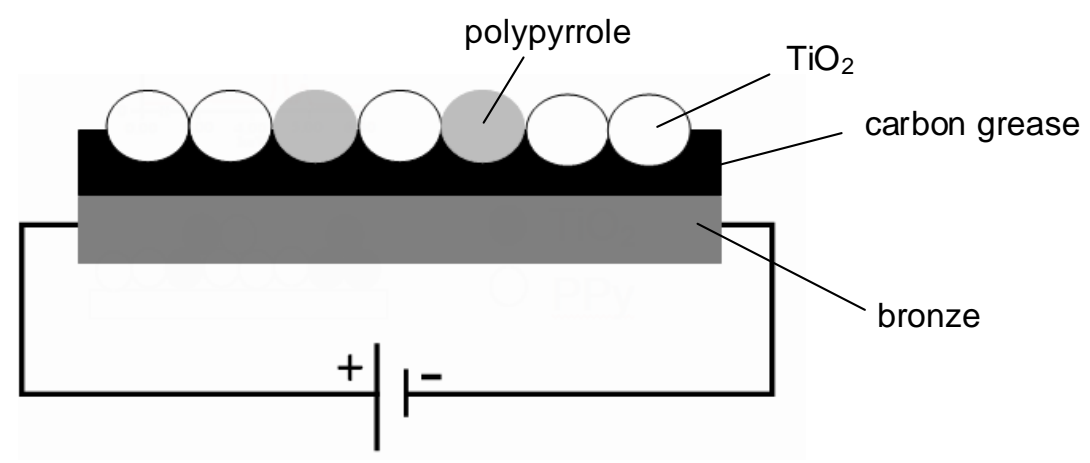

Fig. 1: The schematic representation of the catalyst system induced by electric field.

\subsection{Morphological properties and Ti mapping}

The morphology of the catalyst system was examined using a scanning electron microscope. The distributions of $\mathrm{Ti}$ atoms on the surface of the catalyst system were obtained by SEM EDX mapping (JEOL JSM 840A).

\subsection{The oxidation of benzohydrol}

The oxidation of benzhydrol was carried out using the above catalyst system with and without electric field. Benzohydrol (1 mmol in $10 \mathrm{ml}$ water), $30 \%$ aqueous $\mathrm{H}_{2} \mathrm{O}_{2}$ (5 mmol) were placed in reaction tube and the reaction was performed in oil bath with stirring at $70{ }^{\circ} \mathrm{C}$ for $20 \mathrm{~min}$. After the reaction, the solution was transferred into a separatory funnel and extracted with diethyl ether. GC (Agilent $19091 \mathrm{~N}-133$ ) equipped with a flame ionization detector (FID) was used to identify the reaction product. The voltage and current of electric field measured during the reaction were $5 \mathrm{~V}$ and $2 \mathrm{~A}$, respectively.

\subsection{The adsorption of dye}

The dye used was methylene blue from Sigma. Adsorption was carried out by stirring $20 \mathrm{ml}$ of $2 \mathrm{ppm}$ methylene blue in presence of the above catalyst system with and without electric filed. The voltage and current of electric field applied during the adsorption were $5 \mathrm{~V}$ and 2 $\mathrm{A}$, respectively. The methylene blue solutions were contacted for $1 \mathrm{~h}$ and analyzed spectrophotometrically at $\lambda_{\max }$ of $665 \mathrm{~nm}$. Adsorption experiments were immediately conducted with $1.0 \mathrm{~cm}$ light path quartz cells using PerkinElmer Lambda 900.

\section{RESULTS AND DISCUSSION}

\subsection{Oxidation of benzohydrol with aqueous hydrogen peroxide under electric field}

Fig. 2 shows the results for oxidation of benzohydrol to benzophenone over electrically conducting surface containing titanium dioxide by using hydrogen peroxide under and without electrical field. The catalyst system without electric field showed a low performance for benzophenone production, whereas it exhibits reasonably good performance for this reaction under electric field. The best performance appears to be the catalyst system containing $30 \% \mathrm{TiO}_{2}$ under electric field (see Fig. 2). Note that although the catalyst system containing $30 \% \mathrm{TiO}_{2}$ appears to be best when comparing different loadings, if we replot Fig. 2 in terms of turnover number (TON) (Fig. 3), then $10 \% \mathrm{TiO}_{2}$ appears to be a better than the other $\mathrm{TiO}_{2}$ loading, suggesting that amount of $\mathrm{TiO}_{2}$ at $10 \%$ loading exhibited definite activity. This probably relates to the dispersibility of $\mathrm{TiO}_{2}$ particles on the conducting surface of the catalyst system as shown in Fig. 1. EDX mapping of $\mathrm{Ti}$ (Fig. 2b) shows that $\mathrm{TiO}_{2}$ particles agglomerate into big particles when $\mathrm{TiO}_{2}$ loading is $60 \%$.

Although the adsorption study of benzohydrol on the catalyst system is important to clarify the effect of electric field on catalytic activity, the experimental procedures to demonstrate it seem difficult. The only credible, tough complex, in the present study, we employed the feasible process of adsorption of methylene blue on the catalyst system as a model compound to evaluate the effect of electric field on the adsorption of organic substrates. The effect of the adsorption of the methylene blue on the surface of catalyst system under and without electric field is shown in Fig. 4. It was shown that the electric field induced the adsorption of methylene blue on the catalyst system. The amount of $\mathrm{TiO}_{2}$ led to a considerable decrease of the adsorption of dye because the conducting surface was covered by non-conducting $\mathrm{TiO}_{2}$ particles. Since the electric current flow only in conducting region, a suggestion that can be made is that the dye molecules preferentially adsorb on PPy and carbon grease surfaces. 


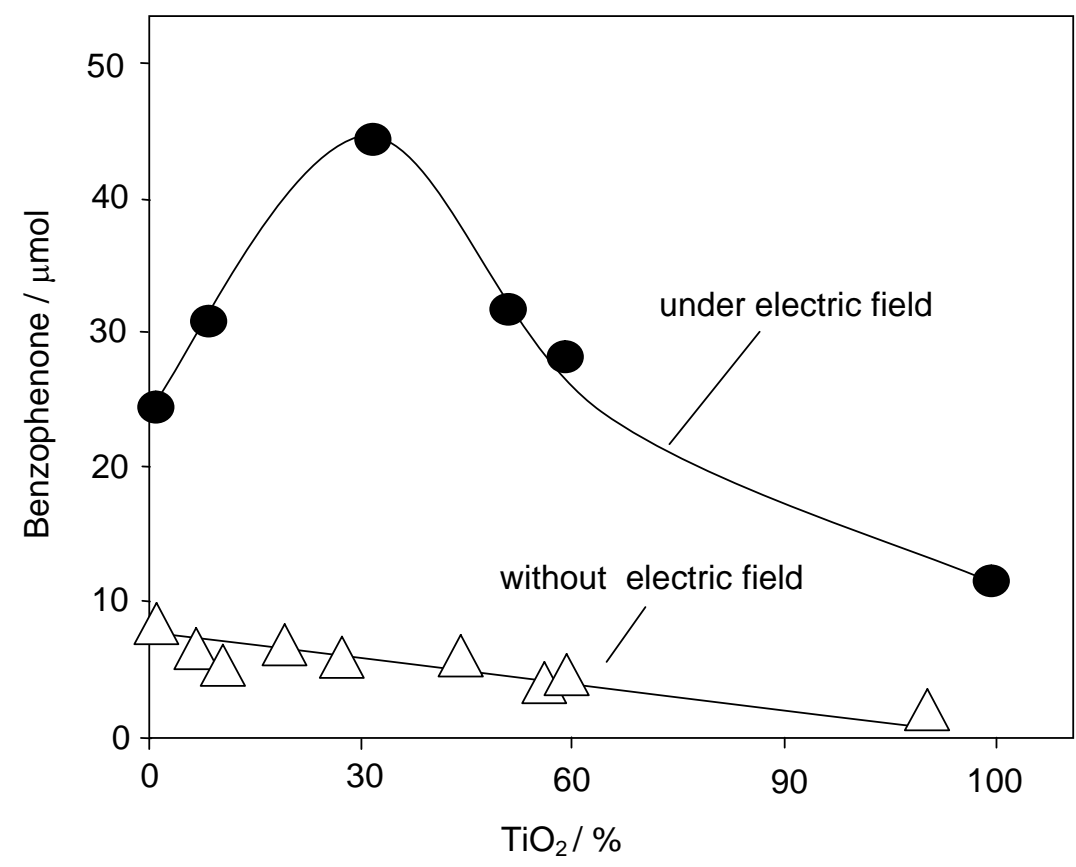

$0 \% \mathrm{TiO}_{2}$
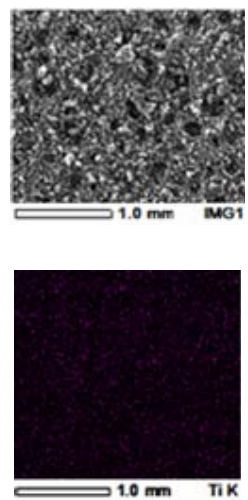

b

\section{a}
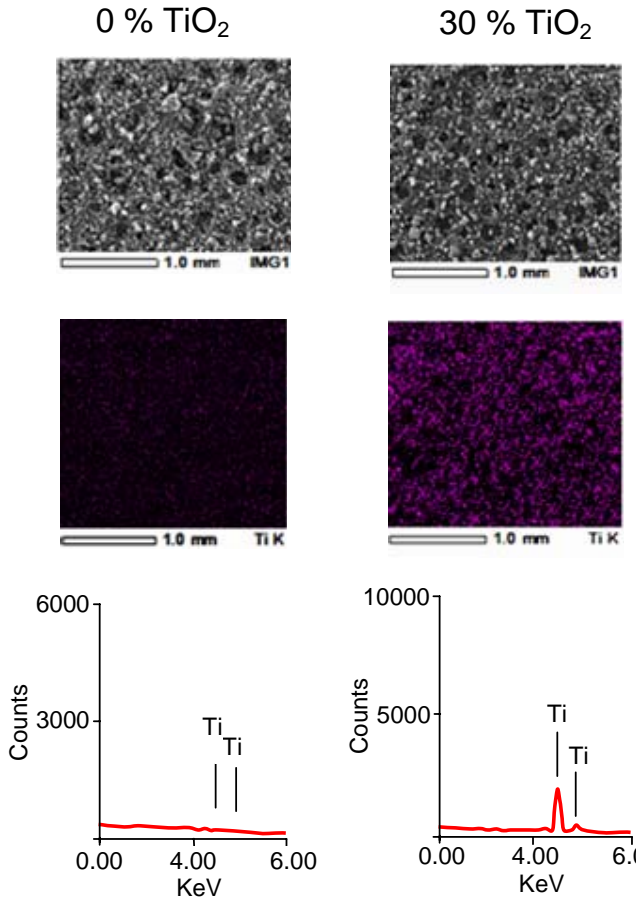

d 00000000
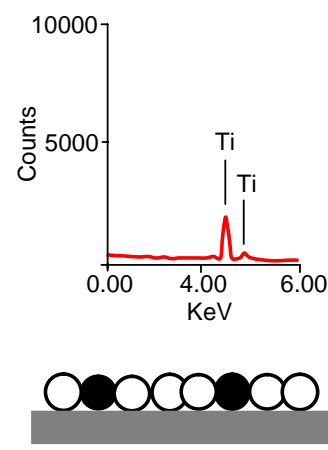

$60 \% \mathrm{TiO}_{2}$
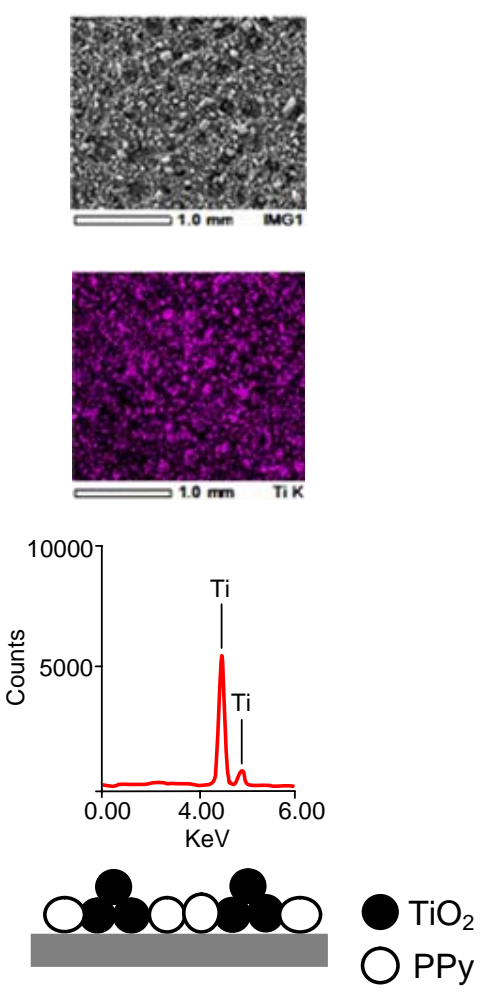

Fig. 2: The yield of benzophenone on the the oxidation of benzohydrol by aqueous hydrogen peroxide. All reactions were carried out at $70{ }^{\circ} \mathrm{C}$ for $20 \mathrm{~min}$. The voltage and current of electric field measured during the reaction are $5 \mathrm{~V}$ and 2 A, respectively. (a) The SEM photographs, (b) EDX mapping, (c) elemental Ti count image and (d) arrangement of $\mathrm{TiO}_{2}$ on the surface of catalyst system. The violet points in the Fig. 2(b) denote Ti atoms. 


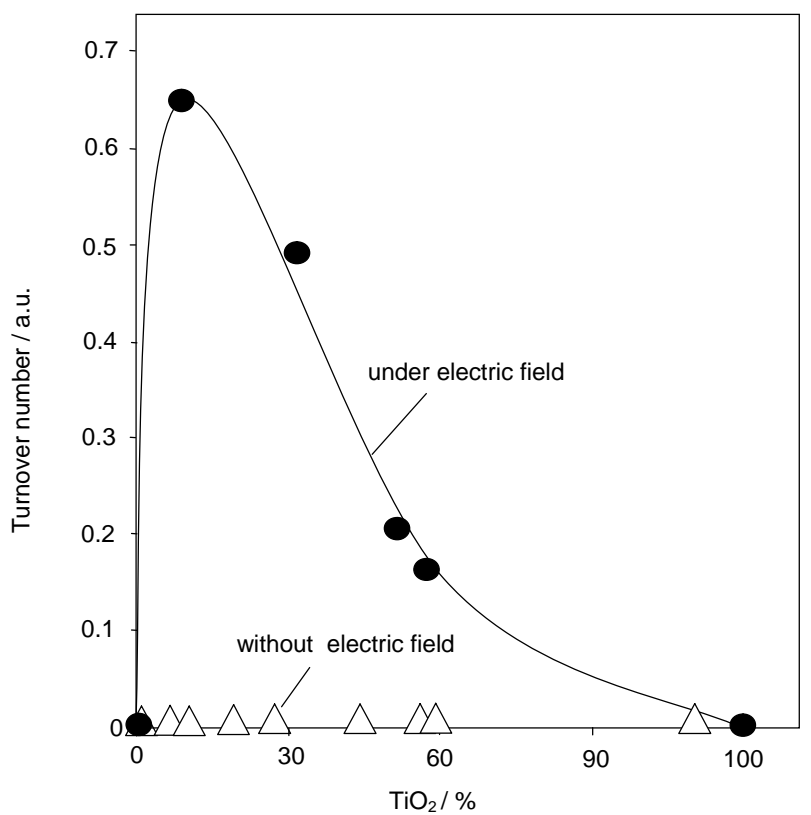

Fig. 3: The turnover number per $\mathrm{Ti}$ in the oxidation of benzohydrol by aqueous hydrogen peroxide. Reaction conditions are the same as given in Fig. 2.

\subsection{The location of the most active oxidation site}

As described above, the catalyst system containing c10-30\% $\mathrm{TiO}_{2}$, effectively catalyzed benzohydrol oxidation by using $\mathrm{H}_{2} \mathrm{O}_{2}$. The simple explanation for the decrease of the catalytic activity of the catalyst systems containing $\mathrm{TiO}_{2}$ above $30 \%$ is that, as the $\mathrm{TiO}_{2}$ loading increases, so does the effective interphase area between the $\mathrm{TiO}_{2}$ particles. This is due to above a certain loading, the $\mathrm{TiO}_{2}$ particles begin to agglomerate and overlap. One suggests that the catalyst system must satisfy the following requirements in order to achieve high catalytic activity: (i) existence of $\mathrm{Ti}$

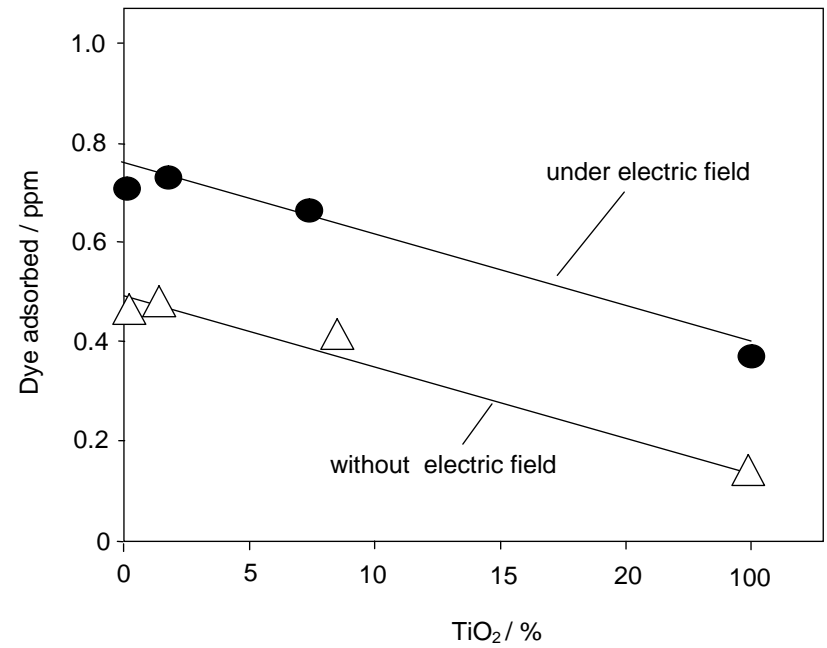

Fig. 4: Concentration of adsorbed methylene blue on the surface of catalyst system containing $\mathrm{TiO}_{2}$

active sites, and (ii) the presence electric field. Therefore, if the catalyst particles exist in the agglomerate form, the number of $\mathrm{Ti}$ active sites which are in contact with conducting surface are limited and efficient oxidation reaction cannot be expected. The use of a certain amount of $\mathrm{TiO}_{2}$ is necessary in order to increase the effective interphase area between the $\mathrm{TiO}_{2}$ particles and conducting surface. On the basis of these results, a model of the catalyst system induced by electric field is proposed (see Fig.5).

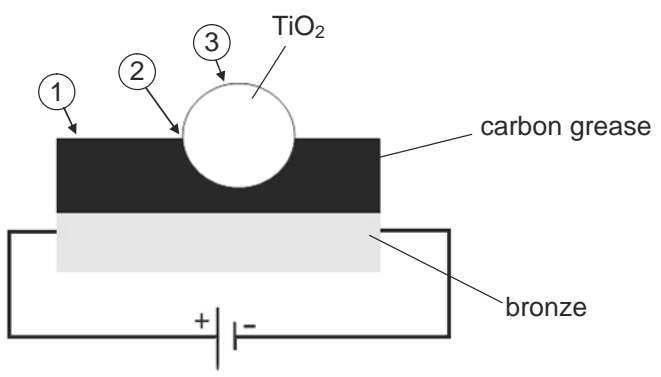
(1) non-active site region
(2) very active site region
(3) active site region

Fig. 5: Proposed model of an effective region for catalytic oxidation reaction induced by electric field.

All the results mentioned above seem consistent with the proposal that claimed the reaction takes place at the effective interphase area between the $\mathrm{TiO}_{2}$ particles and conducting surface. However, the apparent rate of oxidation of benzohydrol was much lower than previously reported [9]. One of the reasons for the low activity in our catalyst is 
the presence of few four-coordinate $\mathrm{Ti}$ species which are considered to be the most active species in the oxidation reaction with $\mathrm{H}_{2} \mathrm{O}_{2}[10,11]$. It should be noted that we used the $\mathrm{TiO}_{2}$ as an easily available material and the catalyst and the reaction conditions have not been optimized. Thus, we have shown that the oxidation reaction could be enhanced by electric field.

\section{ACKNOWLEDGEMENTS}

This research was supported by the Ministry of Science, Technology and Innovation (MOSTI), Malaysia, under the Sciencefund grant No. 03-01-06-SF0326 and the Ministry of Higher Education (MOHE), Malaysia under the Fundamental Research Scheme Grant Vot. 78070.

\section{REFERENCES}

[1] D. R. Rolison, J. Z. Stemple, United States Patent 5397447, 1995

[2] E. Carbonell, M. Duran, A. Lledós, J. Betran, J. Phys. Chem. 95 (1991) 179.

[3] H. J. Kreuzer, Surf. Sci. 246 (1991) 336.

[4] J. H. Block, H.J. Kreuzer, L. C. Wang, Surf. Sci. 246 (1991) 125.

[5] V. J. Lee, Science, 152 (1966) 514.

[6] B. W. Wang, G. H. Xu., Chinese Chem. Lett. 14 (2003) 1236.

[7] G. Pacchioni, J. R. Lomas, F. Illas, J. Mol. Catal. A: Chem. 119 (1997) 263.

[8] Scientific Background on the Nobel Prize in Chemistry 2007: Chemical Processes on Solid Surfaces, The Royal Swedish Academy of Sciences, Stockholm, 2007.

[9] Y. H. Ng, S. Ikeda, T. Harada, Y. Morita, M. Matsumura, Chem. Commun. (2008) 3181.

[10] H. Nur, D. Prasetyoko, Z. Ramli, S. Endud, Catal. Commun. 5 (2004) 725.

[11] H. Nur, S. Ikeda and B. Ohtani, Chem. Commun. (2000) 2235. 